\title{
Forward Modeling Research of Gravity Data Offset in North China Region
}

\author{
Dandan Li ${ }^{1,2}$, Xingong Tang1,2*, Shuai Hou ${ }^{1,2}$, Kui Xiang1,2 \\ ${ }^{1}$ Key Laboratory of Exploration Technologies for Oil and Gas Resources of MOE, Yangtze University, Wuhan, China \\ ${ }^{2}$ Hubei Cooperative Innovation Center of Unconventional Oil and Gas, Wuhan, China \\ Email: *tangxg@yangtzeu.edu.cn
}

How to cite this paper: Li, D.D., Tang, X.G., Hou, S. and Xiang, K. (2019) Forward Modeling Research of Gravity Data Offset in North China Region. Open Journal of Yangtze Gas and Oil, 4, 79-88.

https://doi.org/10.4236/ojogas.2019.42006

Received: April 10, 2018

Accepted: April 16, 2019

Published: April 19, 2019

Copyright $\odot 2019$ by author(s) and Scientific Research Publishing Inc. This work is licensed under the Creative Commons Attribution International License (CC BY 4.0).

http://creativecommons.org/licenses/by/4.0/

(c) (i) Open Access

\begin{abstract}
Due to the complexity and overlap effects of gravity anomalies, the gravity high point always deviates from the real position of the target. Researching the offset characteristics is helpful to determine the right location of gravity anomalies. In this paper, a series of forward models were designed to calculate the offset features under different assumptions. Different density models were established based on the measured gravity data in north China Sunhu area and a variety of methods were tried to eliminate offset effects under different conditions. The results indicate that the gravity anomalies of different density bodies can be separated effectively and the real position of target can be correctly located by using the "layer stripping method".
\end{abstract}

\section{Keywords}

Gravity Exploration, Gravity Offset, Forward Modeling, Potential Field Separation, Digital Filter, Layer Stripping Method

\section{Introduction}

The Earth's gravity field is closely related to the density spatial distribution of material in the inner Earth. The information of gravity field can provide the basic parameter of resources exploration [1] [2] [3]. So far, most of the oil and gas fields discovered in China are based on gravity method. And the application effects of gravity data heavily depend on the potential data process. The filtering effects on gravity and magnetic data operations was first studied by Nettleton (1954), who compared several different approaches in dealing with regional fields [4]. S. Treitel (1967) used the Wiener filtering technique to divide the potential field [5]. Wei (1984) designed a directional ellipse filter that could identify the local and regional fields with different trends [6]. More recently, Guo et al. 
(2012) presented the preferential filtering method for de-noising and anomaly separation of gravity data based on Green's equivalent-layer concept and Wiener filter [7].

A lot of researches on the filtering methods have been made by the scholars both in China and abroad. However, the research on the characteristics of gravity high point offset and its correction methods is still less. In fact, it is common that the gravity high point deviates from the target's real position due to the complexity and overlap effects of gravity anomalies. Xiao et al. (1984) proposed that the location of the geological body would be affected by the regional fields and offset in the actual inversion process [8].

It is important to study the causes of the offset and find appropriate correction methods to make the geological body to its real location. In this paper, on the basis of the real data in North China Sunhu area, some different models were established, then the offset rules of gravity high point under different factors were researched in detail, and finally some methods were carried out to eliminate the offset effect. Among them, the geological modeling is a promoting method to find the shape and location of underground structures. Onur Osman, A. Muhittin Albora et al. $(2007,2016)$ performed Forced Neural Network (FNN) method to find the parameters of a model, and then applied it to synthetic and real data, which acquired a very good result [9] [10].

\section{Potential Field Separation Method}

In this study, two kinds of anomaly separation methods were applied-Regularization filtering and Layer stripping - to separate the anomalies. Regularization filtering method uses regularized stabilization filter factor to perform low-pass filtering on gravity and magnetic data. The filter parameters can be measured directly from the original anomaly profile or the plane contour map [11].

Suppose the measured gravity anomaly is $\Delta g(x, y)$ and its spectrum is $F(u, v)$. The spectrum needs to be multiplied by a "regularization factor" $(W(u, v))$ to separate the anomaly:

$$
W(u, v)=\frac{1}{1+2.75 \cdot \mathrm{e}^{\beta\left(f-f_{0}\right) \lambda_{\mathrm{x}}}}, f=\sqrt{u^{2}+v^{2}}
$$

where $u$ and $v$ denote angular frequencies along $x$ and $y$, respectively.

$\beta \geq 2, f_{0}=1 / \lambda_{0}, \lambda_{0}$ is the maximum wavelength to be filtered out, and $\lambda_{\mathrm{x}}=$ (line number in measuring area -1 ) $\times$ line distance.

For example, the gravity anomaly component in the frequency range of $\left[f_{01}, f_{02}\right]-\Delta g_{\lambda_{01} \lambda_{02}}$ can be obtained by Formulas (2) and (3):

$$
\begin{gathered}
F_{f_{01} f_{02}}(u, v)=F(u, v) \cdot\left\{1-W\left(\beta, f_{01}\right)\right\} \cdot W\left(\beta, f_{02}\right) \\
\Delta g_{\lambda_{01} \lambda_{02}}(x, y)=F^{-1}\left\{F_{f_{01} f_{02}}(u, v)\right\}
\end{gathered}
$$

where, $\mathrm{F}_{f_{01} f_{02}}$ is spectrum in the frequency range of $\left[f_{01}, f_{02}\right], \lambda_{01}$ and $\lambda_{02}$ are the maximum wavelengths corresponding to $f_{01}$ and $f_{02}$, respectively. 
The thought of "Layer stripping method" is to calculate the anomalies caused by the known field sources, and then subtract them from the observed anomalies, which make the separation of remaining anomalies easier, so as to obtain the target anomalies [12].

\section{Forward Modeling}

\subsection{The Characteristics of Gravity High Point Offset}

In order to investigate the characteristics of the gravity anomaly offset, forward calculation has been carried out. Based on the seismic and well logging data (Table 1), a series of geological models of buried hills with different sizes, depths, quantities as well as density differences (Figure 1) are designed to calculate their gravity anomalies.

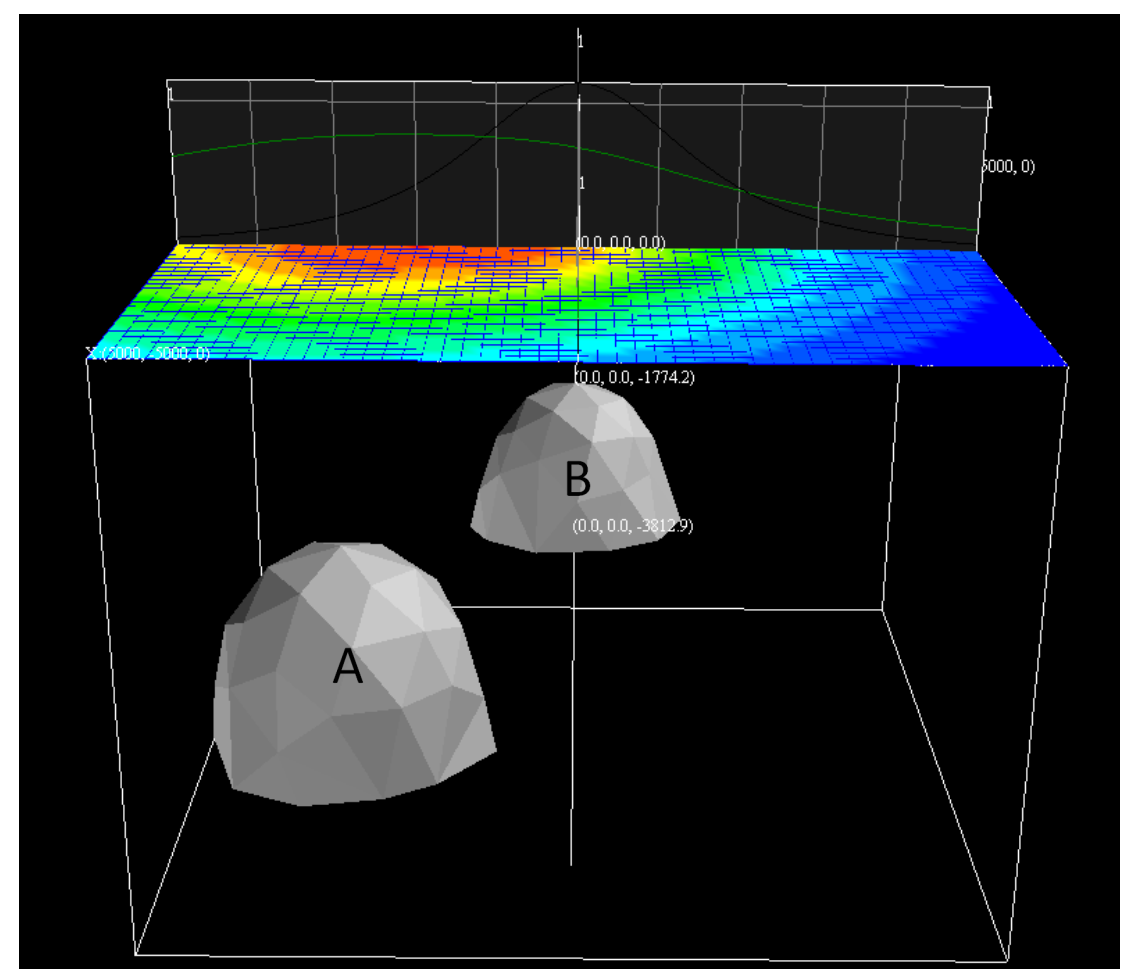

Figure 1. Schematic diagram of model I.

Table 1. Logging density statistics for North China area.

\begin{tabular}{|c|c|c|c|}
\hline Stratigraphy & $\begin{array}{l}\text { Density range } \\
\quad /\left(\mathrm{g} \cdot \mathrm{cm}^{-3}\right)\end{array}$ & $\begin{array}{l}\text { Average density } \\
\qquad /\left(\mathrm{g} \cdot \mathrm{cm}^{-3}\right)\end{array}$ & Drilling wells \\
\hline $\mathrm{N}_{1} \mathrm{~g}$ & $2.237-2.283$ & 2.261 & $\mathrm{Hu} 3,4,5,7,8,9,14,15,17$ \\
\hline $\mathrm{Es}_{2}-\mathrm{Es}_{3}$ & $2.24-2.369$ & 2.34 & Hu $1,2,3,4,5,6,7,8,9,10,13,14,15,17$ \\
\hline $\mathrm{Es}_{4}-\mathrm{Ek}$ & $2.332-2.468$ & 2.42 & $\mathrm{Hu} 1,2,5,6,7,8,9,10,13,14,15,17$ \\
\hline Jx, Chg, Pt & $2.61-2.828$ & 2.69 & $\begin{array}{l}\text { Hu } 1,2,5,6,8 \\
\text { Hu } 9,13,20 x\end{array}$ \\
\hline Ar & $2.548-2.736$ & 2.65 & $\mathrm{Hu} 20 \mathrm{x}$ \\
\hline
\end{tabular}


In the Cartesian coordinate system, the coordinate origin is located directly above the surface of the target body. The $x$ direction is horizontal to the right, the $y$ direction is perpendicular to the paper, and the $\mathrm{Z}$ direction is perpendicular to the xoy plane. Model I (Figure 1) consists of 2 buried hills, which from left to right is named as buried hill A and B (B is target body), respectively. The density difference and coordinates center is $\Delta \rho_{1}=0.17 \mathrm{~g} / \mathrm{cm}^{3}$ and $x_{1}=(0,-3112,-5884)$ respectively for buried hill $\mathrm{A}$ and $\Delta \rho_{2}=0.05 \mathrm{~g} / \mathrm{cm}^{3}, x_{2}=(0,0,-3000)$ for buried hill B.

Figure 2 and Figure 3 show that the gravity high point is shifted from the target (shown in the black box in Figure 3 ) due to the effect of the buried hill A. The offset will lead to the misjudging of the real location of the target in the actual data process, so it is important to study the causes of the deviation and eliminate the offset effect.

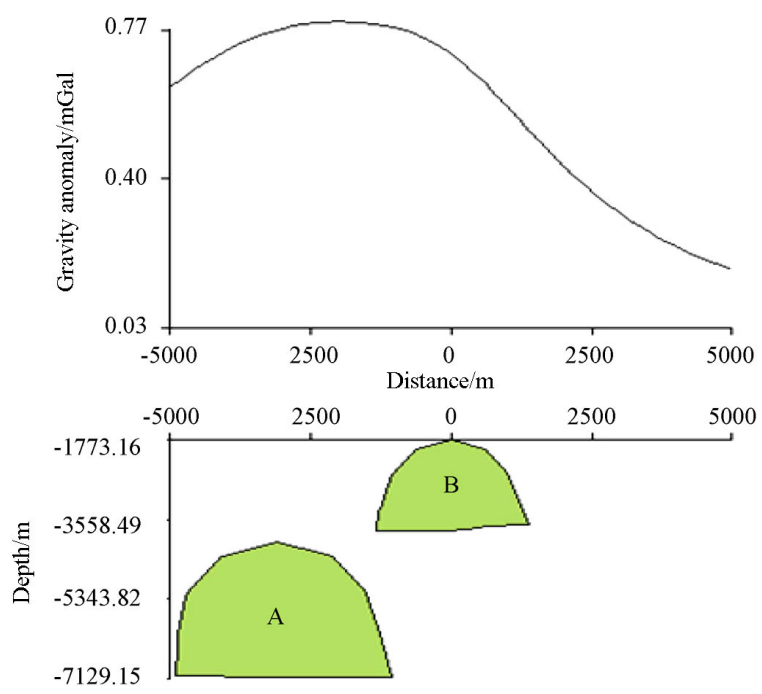

Figure 2. Schematic diagram of model I and its gravity response.

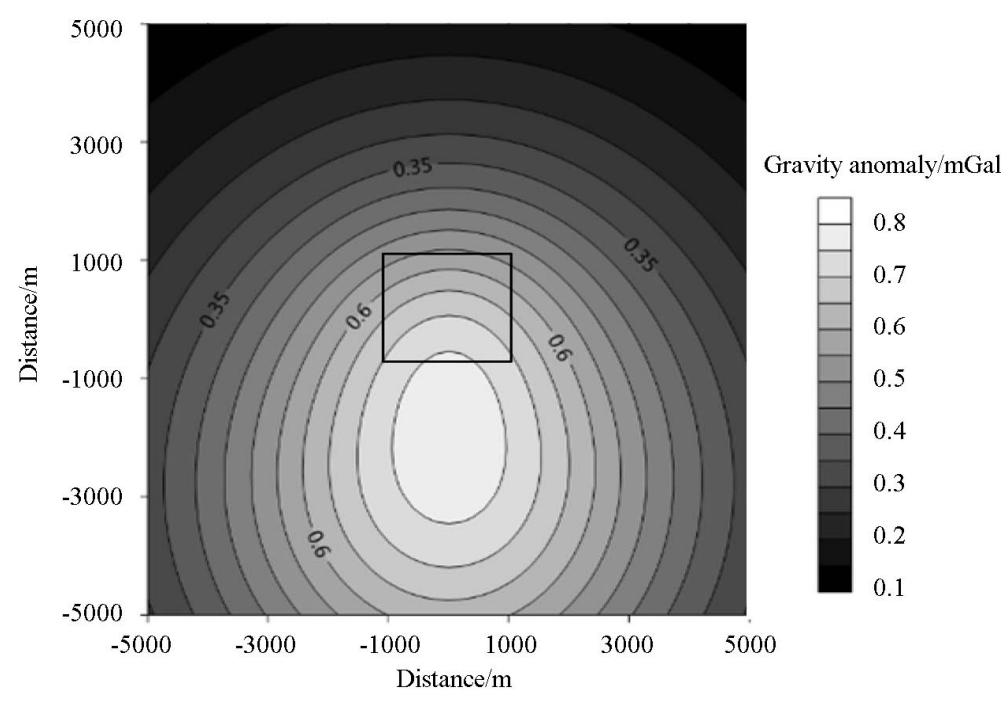

Figure 3. Anomaly contour map of model I. 
In this model, three factors-buried depth, density difference and horizontal distance of density bodies, which maybe the cause of the offset, are studied in detail. And the results are shown in Figures 4-6. It can be illustrated that, with the increase of the depth of buried hill A, the offset of the gravity high point gradually weakens (Figure 4). With the increase of the density difference of buried hill $\mathrm{A}$, the offset gradually strengthens (Figure 5). And the offset gradually strengthens with the increase of the horizontal distance separation of two anomalies. But when the distance increases to a certain extent, the target's gravity high point will appear again, and correspond to the actual location of the geological body (Figure 6).

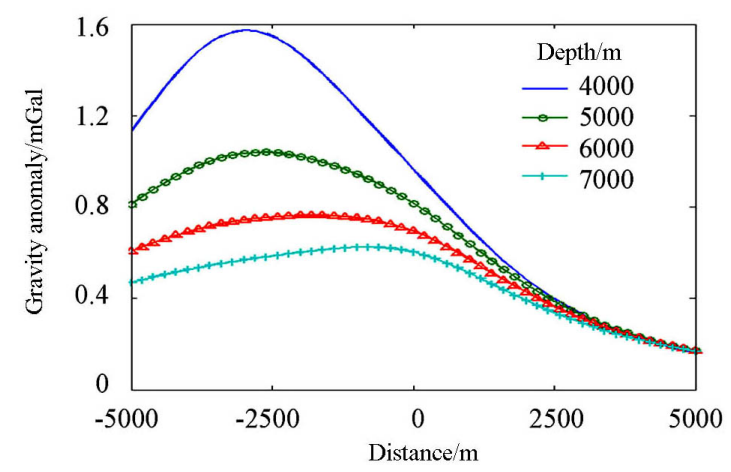

Figure 4. The gravity high point offset in different buried depth of the buried hill A.

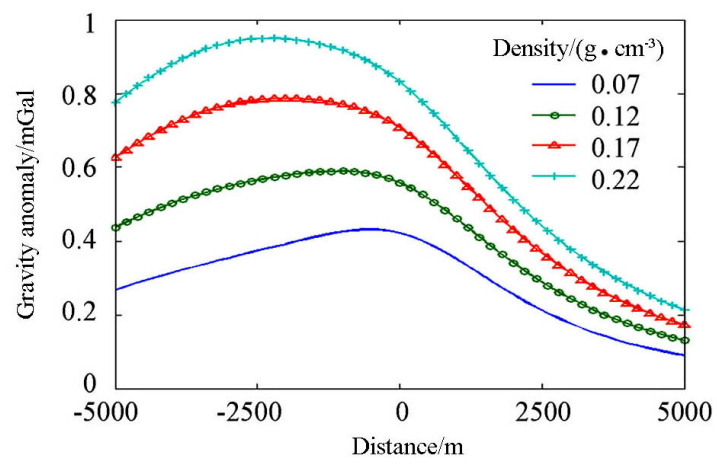

Figure 5. The gravity high point offset in different density of the buried hill A.

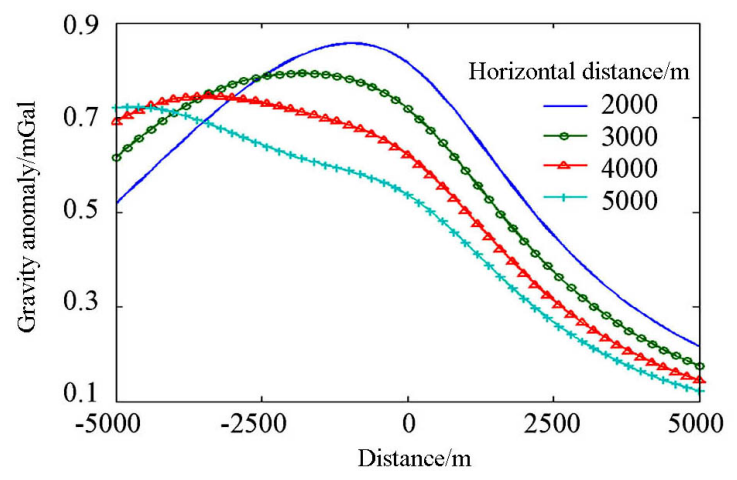

Figure 6. The offset of the target body gravity high point with different horizontal distance. 


\subsection{Elimination of Gravity High Point Offset}

In order to eliminate the offset, the models of three buried hills (the model II and model III) are designed and calculated. In model II (Figure 7), the hills from left to right are buried hill A', B', C' respectively and B' is the target body. Similarly, the Cartesian coordinate system and the same notation are used in Section 3.1. The parameters used in buried hill $\mathrm{A}^{\prime}$ are $\Delta \rho_{1}=0.17 \mathrm{~g} / \mathrm{cm}^{3}$, and $x_{1}=(0,-3112,-5884)$. And the parameters used in buried hill $\mathrm{B}^{\prime}$ are $\Delta \rho_{2}=0.05 \mathrm{~g} / \mathrm{cm}^{3}$, and $x_{2}=(0,0,-3000)$. The parameters in buried hill III are set to be $\Delta \rho_{3}=0.05 \mathrm{~g} / \mathrm{cm}^{3}$, and $x_{3}=(0,2995,-3000)$.



Figure 7. The original and processed gravity responses of model II (upper) and the corresponding schematic geology model (lower).

In model II, the "Layer stripping method" is used to separate the anomaly field, and the "known anomaly" is obtained by Regularization Filtering method, which has been introduced above, then subtract them (?) from the total anomalies. Figure 7 shows that the gravity response of the buried hill B' (target) and C' has been highlighted after the anomaly separation (point line). The gravity high point corresponds roughly to the actual position of geological body.

The model III is one for three buried hills with different sizes, depths and density differences. The parameters used in buried hill A" are $\Delta \rho_{1}=0.17 \mathrm{~g} / \mathrm{cm}^{3}$, and $x_{1}=(0,-3112,-5884)$. The parameters used in buried hill $\mathrm{B}$ " are $\Delta \rho_{2}=0.05 \mathrm{~g} / \mathrm{cm}^{3}$, and $x_{2}=(0,0,-3000)$. The parameters in buried hill $\mathrm{C}^{\prime \prime}$ are set to be $\Delta \rho_{3}=0.05 \mathrm{~g} / \mathrm{cm}^{3}$, and $x_{3}=(0,2995,-1749)$. 
Model III is demonstrated in Figure 8. The gravity high point of the buried hill B" is shift to the left (full line). The buried hill C" of small size and shallow burial only shows a small protrusion on the response curve. Similarly, the "Layer Stripping method" and Regularization Filtering are used to deal with abnormal data. After this procedure is repeated twice, the offset phenomenon has been significantly weakened (point line), while the local response by buried hill C" has been effectively eliminated. A large-scale anomaly of the buried hill A" has suppressed as well. The anomaly of the target is correctly extracted out.

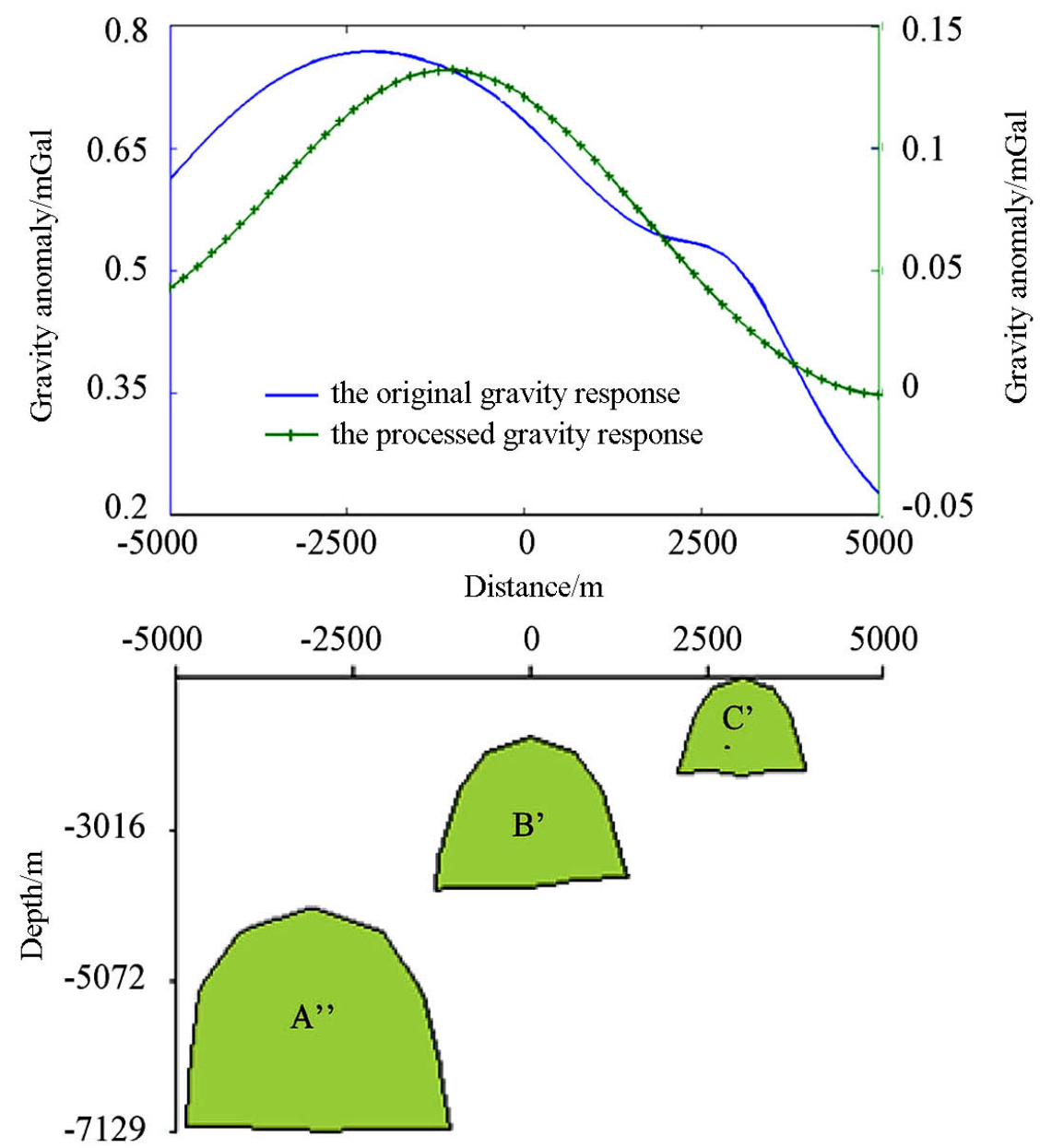

Figure 8. The original and processed gravity responses of model III.

In order to verify the effect of the Layer Stripping method, we use this method to research the real gravity data of Sunhu area of north China region. The results are shown in Figure 9 and Figure 10. And Figure 9 shows the original Bouguer gravity anomaly data. The gravity anomaly of the target area, which is shown in the black box, is hardly shown due to its small size and large buried depth. Figure 10 shows the residual gravity anomaly which has been processed by the Layer Stripping method. It can be clearly seen that the anomaly of the target has been highlighted after the gravity field separation. The anomaly is consistent with the target high point of seismic exploration. 
D. D. Li et al.

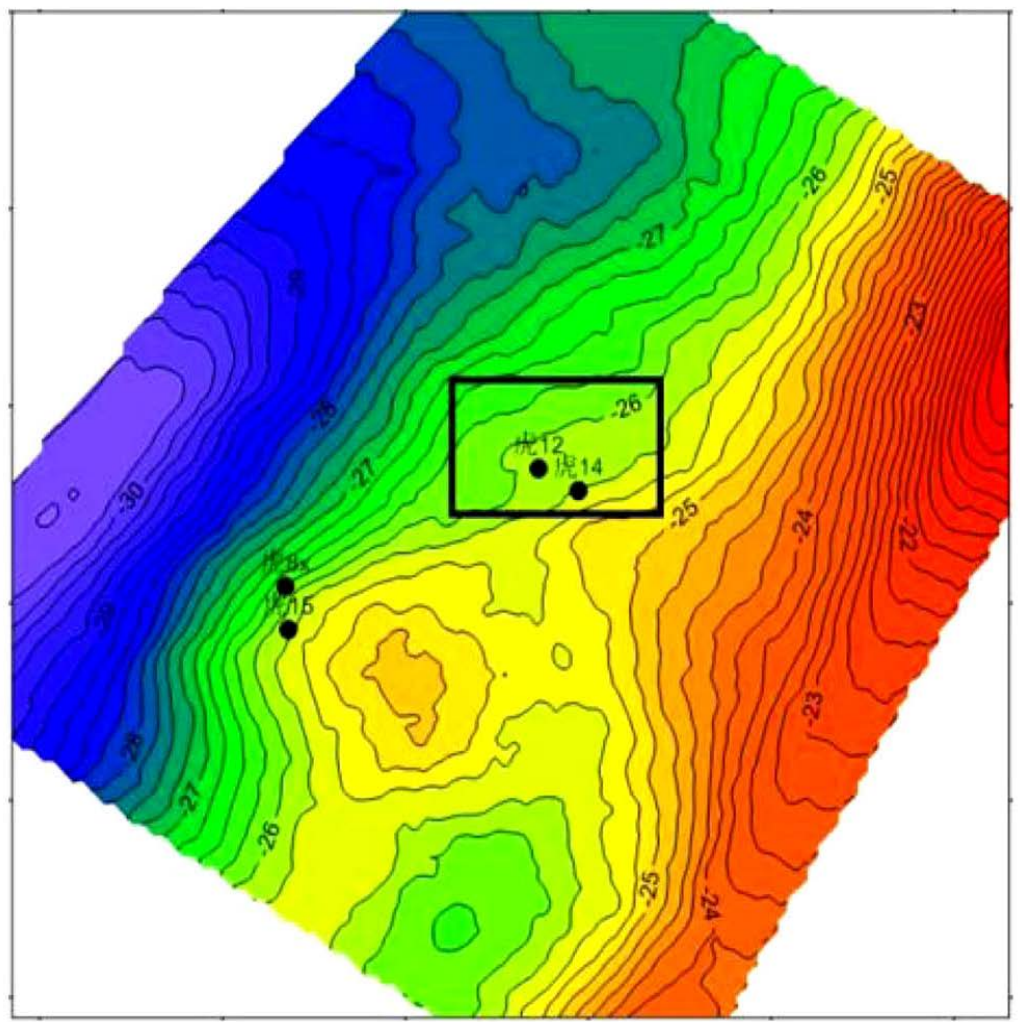

Gravity anomaly/mGal

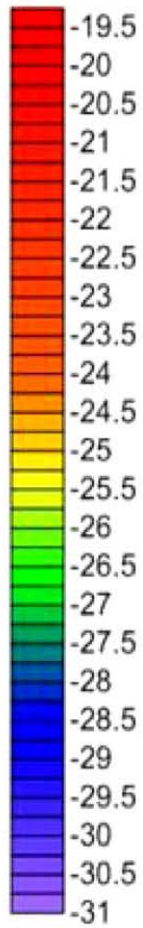

Figure 9. The original Bouguer gravity anomaly.

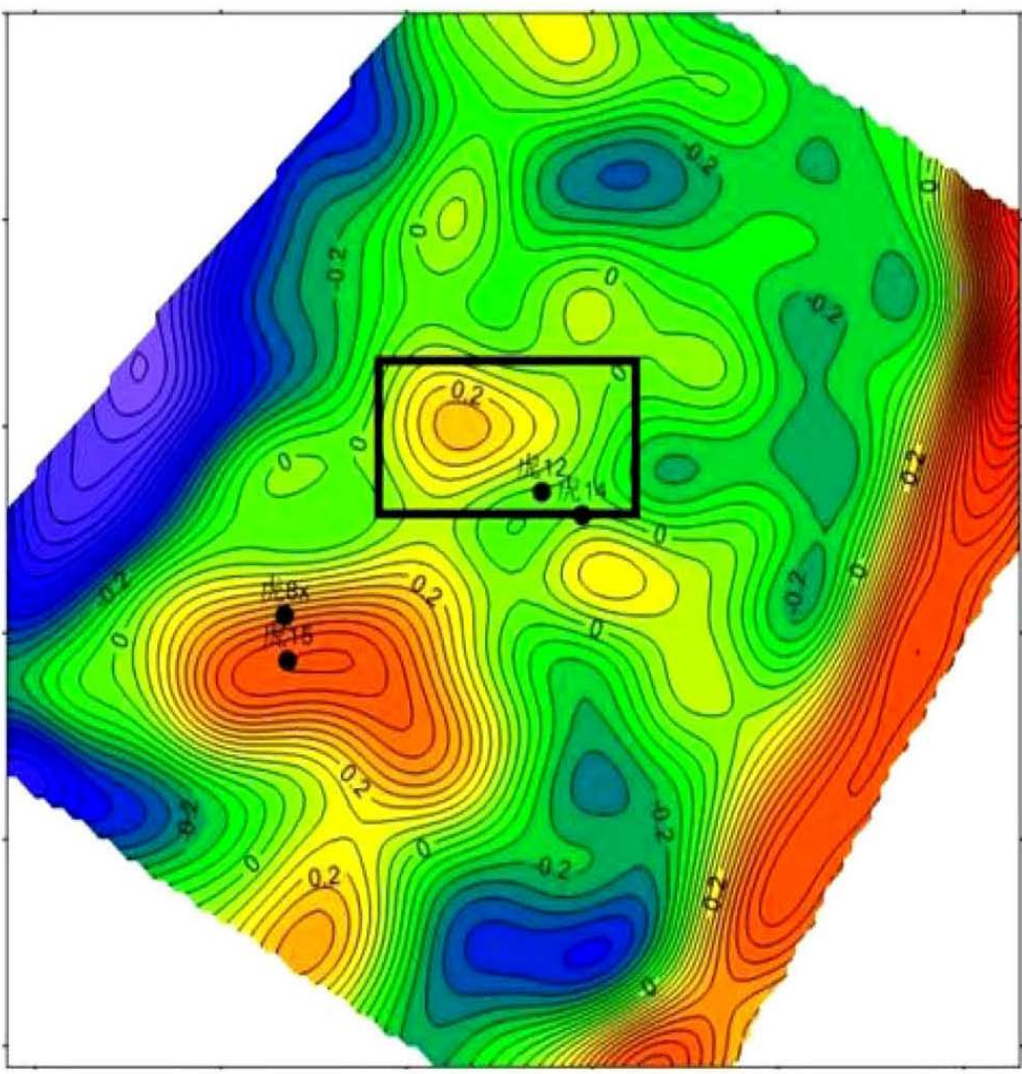

Gravity anomaly/mGal

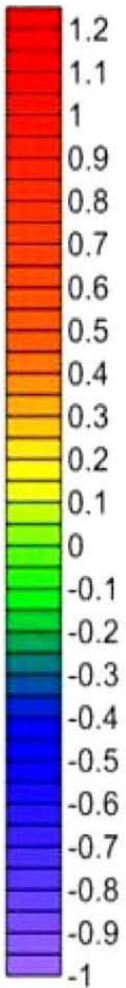

Figure 10. Residual gravity anomaly. 


\section{Conclusions}

On the basis of a series of gravity forward models, the characteristics of gravity high point offset in multiple anomalies with different depths, density differences and distances were calculated and discussed in detail. Regularization Filtering and Layer Stripping methods were used to separate different anomalies to correct the gravity offset. By forward calculations, the conclusions can be made as follows.

1) The model results show that, the offset of the target body's gravity high point weakens with the increase of the buried depth, strengthens with the increase of the density difference and the horizontal distance between the target bodies.

2) By calculation of a series of geologic bodies in different parameters, it is illustrated that the Layer stripping method can effectively eliminate the influence of offset, which is helpful to determine the right location of gravity anomalies and it is of great significance to the processing and interpretation of actual gravity data.

\section{Acknowledgements}

This research is financially supported by the National Natural Science Foundation of China (41674107, 41874119, 41574064), National Key Research and Development Program of China (2017YFB0202904).

\section{Conflicts of Interest}

The authors declare no conflicts of interest regarding the publication of this paper.

\section{References}

[1] Ouyang, Y.Z. (2013) On Key Technologies of Data Processing for Air-Sea Gravity Surveys. Ph.D. Thesis, Wuhan University, Wuhan.

[2] Xiao, F. (2009) Study on Gravity Data Processing Method and Apply It to Gravity Prospecting for Sylvite Mine. Ph.D. Thesis, Jilin University, Jilin.

[3] Wang, M.J. (1994) New Development of Gravity Prospecting in China. Chinese Journal of Geophysics, 37, 353-360.

[4] Nettleton, L.L. (1954) Regionals, Residuals, and Structures. Geophysics, 19, 10-22. https://doi.org/10.1190/1.1437966

[5] Jiang, F.Y. (2008) Studying on Filtering Technique in Potential Field Data Processing and Its Application. Ph.D. Thesis, Jilin University, Jilin.

[6] Wei, X.Q. (1984) Application of Directional Ellipse Filter in Gravity Data Processing. Oil Geophysical Prospecting, 6, 556-566.

[7] Guo, L.H., Meng, X.H., Shi, L. and Chen, Z.X. (2012) Preferential Filtering Method and Its Application to Bouguer Gravity Anomaly of Chinese Continent. Geophys, 55, 4078-4088.

[8] Xiao, Y.M. and Zhang, L.X. (1984) Application of Normalized Gravity Gradient Method in Oil and Gas Exploration. Oil Geophysical Prospecting, 3, 
247-254.

[9] Osman, O., Albora, A.M. and Ucan, O.N. (2007) Forward Modeling with Forced Neural Networks for Gravity Anomaly Profile. Mathematical Geology, 39, 593-605. https://doi.org/10.1007/s11004-007-9114-8

[10] Albora, A.M. and Osman, O. (2016) Modeling of Turkey-Manyas Region Using Forced Neural Networks. Journal of Scientific and Engineering Research, 3, 567-573.

[11] (2015) RGIS for Gravity Magnetic and Electric Data Processing User Manual. China Geological Survey Bureau of Development Research Center.

[12] Hammer, S. (1963) Deep Gravity Interpretation by Stripping. Geophysics, 28, 369-378. https://doi.org/10.1190/1.1439186

Submit or recommend next manuscript to SCIRP and we will provide best service for you:

Accepting pre-submission inquiries through Email, Facebook, LinkedIn, Twitter, etc. A wide selection of journals (inclusive of 9 subjects, more than 200 journals)

Providing 24-hour high-quality service

User-friendly online submission system

Fair and swift peer-review system

Efficient typesetting and proofreading procedure

Display of the result of downloads and visits, as well as the number of cited articles Maximum dissemination of your research work

Submit your manuscript at: http://papersubmission.scirp.org/

Or contact ojogas@scirp.org 